\title{
Variation of antioxidant/detoxification enzyme activities in response to benzo[a]pyrene in the gazami crab Portunus trituberculatus
}

\author{
Lei LI, Mei JIANGa and Xinqiang SHEN \\ East China Sea Fisheries Research Institute Chinese Academy of Fishery Sciences, Shanghai, P.R. China
}

Received 3 June 2015; Accepted 13 August 2015

\begin{abstract}
Responses of four toxicological indices (7-ethoxyresorufin-O-deethylase, EROD; glutathione S-transferase, GST; superoxide dismutase, SOD; and malondialdehyde, MDA) were studied in Portunus trituberculatus gill and liver during enrichment with benzo(a)pyrene $(\mathrm{BaP})$ release at day 15. During $\mathrm{BaP}$ enrichment, toxicological indices in the gill and liver the 0.05 and $0.45 \mu \mathrm{g} \mathrm{L}^{-1}$ test groups were all significantly induced at day $1(P<0.05)$. Induction degree was positively proportional to exposure concentration. The EROC, GST and SOD activities first increased and then decreased. By contrast, liver SOD activity continuously increased. The MDA content in both gill and liver also continuously increased. EROD, GST, and SOD activities reached the peak levels earlier in the gill than in the liver. Enzyme activity and MDA content in the gill were lower than those in the liver. During release of BaP, SOD activity in the gill of the $0.45 \mu \mathrm{g} \mathrm{L}^{-1}$ test group and SOD activity in the liver of both test groups were significantly higher than those in the control group $(P<0.05)$. The toxicological indices in the gill and liver could recover to normal levels $(P>0.05)$. The gill of $P$. trituberculatus is more sensitive to $\mathrm{BaP}$ than the liver, but both organs could recover from our experimental $\mathrm{BaP}$ exposure.
\end{abstract}

Keywords: Portunus trituberculatus / Benzo(a)pyrene / Gill / Liver / Toxicological index

\section{Introduction}

Benzo[a]pyrene (BaP), a polycyclic aromatic hydrocarbon $(\mathrm{PAH})$ in the marine environment, has extensive distribution and shows the strongest carcinogenicity among marine PAHs. Pyrolysis and incomplete combustion of organic matters are the main sources of $\mathrm{BaP}$. BaP has a certain correlation with other PAHs and is a representative PAH substance (Reynaud et al. 2006). BaP from different sources are difficult to degrade in the natural environment after they have entered a water body because of their stable physical and chemical properties. Because of their strong lipotropy, they can accumulate in living bodies and enter the ecosystem through food chains (Kidd et al. 1998). BaP enters in living bodies and is biologically converted, forming various intermediate metabolites. Most of them are electrophilic compounds that have high activity, can interact with macromolecules in living bodies (e.g., proteins and nucleic acids), and have strong genotoxicity and immunotoxicity (Carlson et al. 2002). BaP can cause oxidative stress by inducing a high level of reactive oxygen species (ROS), which could be related to cellular damage and apoptosis (Bo et al. 2012), and it can also cause embryo toxicity and immuno-

a Corresponding author: jerrylee200224@126.com modulation in both invertebrates and vertebrates (Gopalakrishnan et al. 2009).

In recent years, biomarkers, defined as quantitative measures of changes at various biological levels indicative of exposure to pollutants, have been proposed as sensitive tools for measuring biological effects in environmental quality assessment (Lisa et al. 2009). It is widely known that BaP toxicity is often mediated by its biotransformation to reactive intermediates that in turn react with macromolecules leading to oxidative damage and function alteration. All these mechanisms can be monitored by means of biomarkers (Carlos et al 2013). BaP toxic effects are directly reflected in the levels of 7-ethoxyresorufin-O-deethylase (EROD) (Beyer et al. 1996), glutathione S-transferase (GST) (Fitzpatrick et al. 1995), superoxide dismutase (SOD) (Ren et al. 2015), and lipid peroxidation (LPO) (Thomas et al. 1990); these toxicology biomarkers are identified as the most promising biological means of monitoring organic pollution. These biomarkers show highly sensitive biological responses and could provide early warning against the potential toxicity of organic pollutants (Walker et al. 1998).

The gazami crab, Portunus trituberculatus is a euryhaline crab species, surviving in wide-range salinity conditions. It is a commercially important fishery species widely distributed in the coastal waters of Korea, Japan, China, through Southeast 
Asia, to the Indian Ocean, and it was also an important aquaculture species in China (Xu and Liu 2011). This species is a bottom-dwelling crab in which lipophilic contaminants, such as organochlorinated compounds, tend to accumulate in high concentrations because of its considerable fat content (Ferreira and Vale 1998). This species is abundant in marine ecosystems, and they are also subjected to exploitation by fisheries in the area, being part of the human diet.

Biomarkers have been widely applied in research on the toxicological effect of $\mathrm{BaP}$ on marine bivalve mollusk (Akcha et al. 2000), fishes (Pereira et al. 2010), shrimps (Silva et al. 2013), and crabs (Van Oosterom et al. 2010). They are also used to evaluate the health risks of $\mathrm{BaP}$ in an aquatic ecosystem. However, no comparative research concerning BaP effect on toxicological indices in different tissues of Portunus trituberculatus had yet been conducted. The main goal of this study was to evaluate the effects of exposure to $\mathrm{BaP}$ on the detoxification process and the antioxidant defense system was tested in gazami crab (Portunus trituberculatus). To this end, responses of toxicological indices in P. trituberculatus gill (a respiratory organ) and liver (an important detoxification metabolism organ) to $\mathrm{BaP}$ stress and the mechanism underlying BaP toxicity were explored.

\section{Materials and methods}

\subsection{Experimental organisms}

Healthy crabs Portunus trituberculatus (averaging $10.89 \pm$ $2.20 \mathrm{~g}$ in body weight) were obtained from a commercial farm in Qidong, Jiangsu, China and acclimatized for at least one week in seawater $\left(23.6 \pm 1.5^{\circ} \mathrm{C}\right)$ prior to the experiment. During acclimation, the crabs were fed daily with a commercial crab food (Haiyang, China) daily at a rate of $2 \%$ body weight per day.

\subsection{Chemicals}

BaP was bought from Sigma-Aldrich Corporation, USA. Acetone was used at a certain concentration as a cosolvent to prepare a mother liquor.

\subsection{Exposure design}

The experiment was divided into enrichment and release periods. Each period lasted for day 15. After determining BaP concentration during the pre-test, the mother liquor was diluted to different concentrations with filtered seawater. A total of four groups were set up, including 2 test groups, 1 seawater control group, and 1 acetone control group (acetone volume ratio $<0.01 \%$ ). Each group was used in three repeated tests. The $\mathrm{BaP}$ concentrations were $0.45,0.05$, and $0 \mu \mathrm{g} \mathrm{L}^{-1}$. The exposure concentrations of $\mathrm{BaP}$ were based on the concentration of $\mathrm{BaP}$ in the coastal seawater, surface sediments in China as well as BaP (Huang et al. 2012). Sixty P. trituberculatus were placed in each container and supplied with oxygen $24 \mathrm{~h}$ a day. Dissolved oxygen concentration was higher than $5.00 \mathrm{mg} \mathrm{L}^{-1}$, and water temperature during the test varied in the range of $23.60{ }^{\circ} \mathrm{C}-25.40^{\circ} \mathrm{C}$.

Enrichment period: the enrichment experiment was carried out using a semi-static method. Seawater $(100 \mathrm{~L})$ was added and completely changed every $24 \mathrm{~h}$. Abnormal or dead P. trituberculatus samples were fished out promptly when seawater was changed. Before the experiment, $P$. trituberculatus samples were collected to assess BaP background level. The samples were fed with certain amounts of mixed feeds at $2 \%$ of $P$. trituberculatus weight (Qingdao Liuhe Fodder Co., Ltd.) daily at a fixed time (8:00 and 18:00). Test solutions were re-prepared according to setting concentration series. Three $P$. trituberculatus samples were collected at days $0,1,5,10$, and 15. The gills and livers of these samples were obtained and immediately frozen in liquid nitrogen.

Release period: after the enrichment experiment, the test solutions in every container were discharged. The BaP released in $P$. trituberculatus bodies was assessed under flowing water (flow rate: $3.6 \mathrm{~L} \mathrm{~h}^{-1}$ ). P. trituberculatus samples were fed with a certain amount ( $2 \%$ of $P$. trituberculatus weight) of feeds at a fixed time (8:00 and 18:00). Three P. trituberculatus samples were collected at days 18,20,25, and 30. The gills and livers of these samples were collected and immediately frozen in liquid nitrogen.

\subsection{Sample preparation and testing of toxicological indices}

\subsubsection{Sample preparation}

Gill and liver samples were placed in pre-cooled $\left(0{ }^{\circ} \mathrm{C}-\right.$ $\left.4{ }^{\circ} \mathrm{C}\right)$ phosphate buffer $\left(\mathrm{Na}_{2} \mathrm{HPO}_{4} \cdot 12 \mathrm{H}_{2} \mathrm{O} 0.125 \mathrm{~mol} \mathrm{~L}^{-1}\right.$, $\mathrm{KH}_{2} \mathrm{PO}_{4} 0.125 \mathrm{~mol} \mathrm{~L}^{-1}$, and $\mathrm{Na}_{2}$ EDTA $0.05 \mathrm{~mol} \mathrm{~L}^{-1}$; $\mathrm{pH} 7.7$ ) before homogenization in ice bath for $3 \mathrm{~min}$ at a rotation speed of $12000 \mathrm{r} \mathrm{min}^{-1}$. The homogenate was centrifuged for $20 \mathrm{~min}$ at $10000 \mathrm{r} \mathrm{min}^{-1}\left(4{ }^{\circ} \mathrm{C}\right)$. Supernatant was collected to estimate EROD and GST activities.

\subsubsection{EROD assay}

EROD activity was measured according to Pohl and Fouts (1980). The reaction mixture contained $100 \mu \mathrm{l}$ supernatant, $1 \mathrm{ml} 0.5 \mu \mathrm{M}$ ethylresorufin, $10 \mu \mathrm{l} 6 \mathrm{mM}$ NADPH AND $1.88 \mathrm{ml}$ phosphate buffer $\left(0.125 \mathrm{~m} \mathrm{pH} 7.7\right.$, containing $\mathrm{Na}_{2}$ EDTA, $0.05 \mathrm{~m}, 2-4{ }^{\circ} \mathrm{C}$ ), allowed to proceed for $10 \mathrm{~min}$ at $\mathrm{RT}$, and stopped by the addition of $0.5 \mathrm{ml}$ carbinol. Incubation vials were centrifuged to remove precipitated microsomal protein,and supernatants were transferred to vials for meansurement of resorufin concentrations in a luminescence spectrometer (Model LS55, Perkin-Elmer of UK) at an exciation wavelength of $560 \mathrm{~nm}$ and an emission wavelength of $580 \mathrm{~nm}$. Resorufin was identified and concentrations were calculated by comparison to retention times and responsed of resorufin standards.Blanks corresponded to $t=0 \mathrm{~min}$ and quantification was achieved with standard addtitions of resorufin. 


\subsubsection{GST activity assay}

GST activity was determined in the cytosolic fraction as described by Lemaire et al. (1996), using 1-chloro-2,4dinitrobenzene (CDNB) as substrate (Habig et al. 1974). The reaction mixture contained $200 \mu$ l supernatant, $2 \mathrm{ml}$ phosphate buffer (0.125 mol L-1, pH 7.7), 0.2 mM CDNB and 0.2 mM GSH. The reaction was initiated by the addition of $10 \mathrm{Al}$ sample at $25{ }^{\circ} \mathrm{C}$. The increase in absorbance was recorded at $340 \mathrm{~nm}$ wavelength during $3 \mathrm{~min}$. A unit of GST activity was defined as the amount of glutathione conjugate with $1 \mathrm{nmol}$ GSH and CDNB $\mathrm{min}^{-1} \mathrm{mg}^{-1}$ protein (mmol 2,4-dinitrophenyl glutathione/mg protein/min).

\subsubsection{SOD activity assay}

SOD activity was examined using on the method described by Orbea et al. (2002), which is based on the measurement of the inhibition of the reduction rate of cytochrome $\mathrm{c}$ by the superoxide radicals that are generated by the xanthinexanthine oxidase system. The specific activity was calculated as $\mathrm{U} \mathrm{mg}^{-1}$ protein

\subsubsection{MDA content}

Liver samples were placed in $0{ }^{\circ} \mathrm{C}-4{ }^{\circ} \mathrm{C}$ Tris- $\mathrm{HCl}(\mathrm{pH}=$ $7.4,50 \mathrm{mmol} \mathrm{L}^{-1}$ ) buffer for $3 \mathrm{~min}$, and ice-bath homogenized at a rotation speed of $12000 \mathrm{r} \mathrm{min}^{-1}$. The homogenate was centrifuged for $10 \mathrm{~min}$ at $3000 \mathrm{r} \mathrm{min}^{-1}$, and the supernatant was collected to determine the MDA content (Li Kang et al. 2000).

\subsection{Data processing and analysis}

Data were subjected to ANOVA forfinding out the differences in the activity of enzyme before and after exposure and within the groups. The key test was used for finding differences among the activity of enzymes. The biochemical results are reported as mean $\pm \mathrm{SE}$. The differences were regarded as statistically significant at $P$-values between 0.001 and 0.05 .

\section{Results and analysis}

\subsection{Feasibility of acetone as BaP cosolvent}

Acetone was used to dissolve BaP. No significant difference in toxicological indices was observed between the acetone group and the control group $(P>0.05)$, as shown in Figures 1-4. Thus, acetone could be used as a cosolvent.

\subsection{Induction of BaP on EROD activity of Portunus trituberculatus gill and liver}

During the enrichment period, EROD activity in the gill and liver of the 0.45 and $0.05 \mu \mathrm{g} \mathrm{L}^{-1}$ test groups were significantly induced at day $1(P<0.05)$. EROD activity in the gills
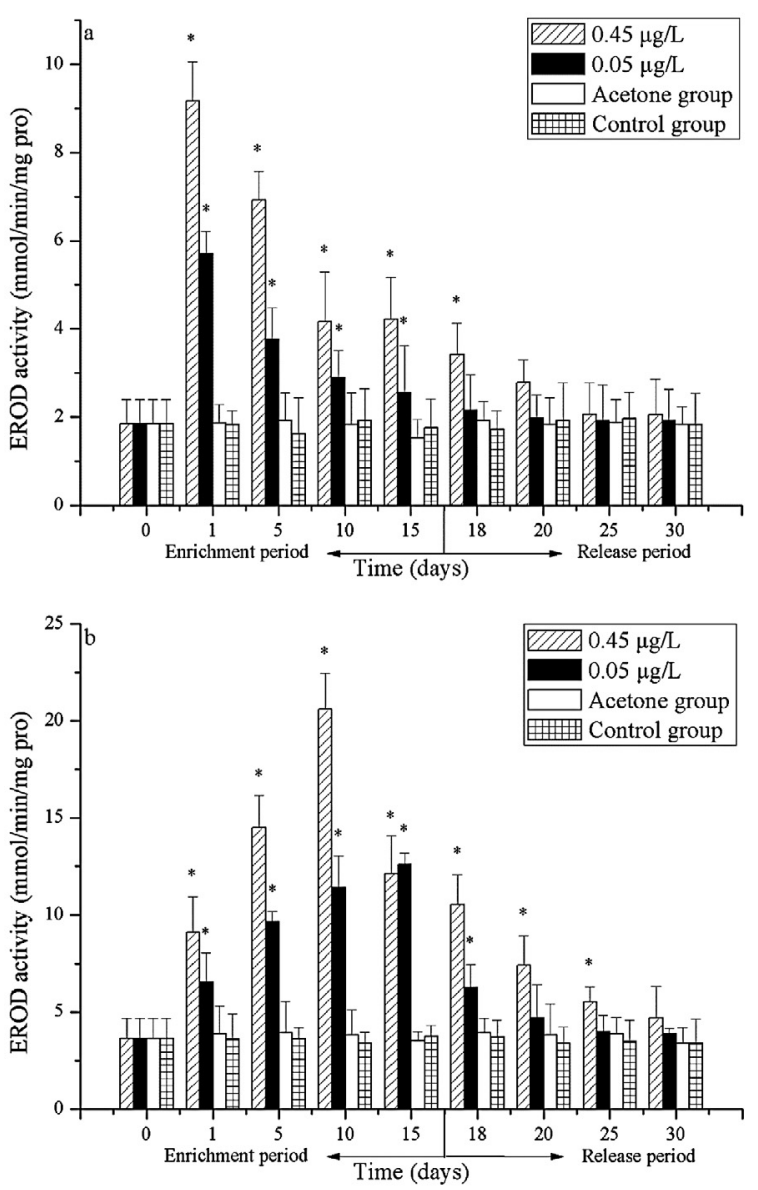

Fig. 1. Effect of BaP on EROD activity of gill (a) and liver (b). Note: Single asterisk $(*)$ indicates significant difference between treatment groups and control group $(P<0.05)$ (Same below).

of samples in both test groups reached peak level at day 1. Peak levels were 4.96 and 3.09 times higher than at day 0. Subsequently, EROD activity in the gill continuously declined and stabilized at day $10(P<0.05)$. EROD activity in the liver of the two test groups continuously increased. EROD activity in the liver of the $0.45 \mu \mathrm{g} \mathrm{L}^{-1}$ test group reached the peak level at day 10, and this level was 5.62 times higher than that at day 0. Afterward, EROD activity declined, but this activity was still significantly higher than in the control group at day 15 $(P<0.05)$. EROD activity in the liver of the $0.05 \mu \mathrm{g} \mathrm{L}{ }^{-1}$ test group peaked at day 15 , during which activity was 3.44 times higher than that at day 0. However, EROD activity in the liver of the $0.05 \mu \mathrm{g} \mathrm{L}^{-1}$ test group was not significant different from that at day $10(P>0.05)$. During the entire enrichment period, the EROD activity in the $0.05 \mu \mathrm{g} \mathrm{L}^{-1}$ test group was less induced compared with that of the $0.45 \mu \mathrm{g} \mathrm{L}^{-1}$ test group. During the release period, EROD activity in the gill and liver of the 0.45 and $0.05 \mu \mathrm{g} \mathrm{L}^{-1}$ test groups continuously decreased. In the gill, the EROD activity of the $0.45 \mu \mathrm{g} \mathrm{L}^{-1}$ test group recovered to the level of the control group at day $25(P>0.05)$. By contrast, the EROD activity of the $0.05 \mu \mathrm{g} \mathrm{L}^{-1}$ test group recovered at day $18(P>0.05)$. For $P$. trituberculatus liver, EROD activity of the $0.45 \mu \mathrm{g} \mathrm{L}^{-1}$ test group recovered to the level of the control group at day $30(P>0.05)$, whereas that of the $0.05 \mu \mathrm{g} \mathrm{L}^{-1}$ test group recovered at day $20(P>0.05)$. 

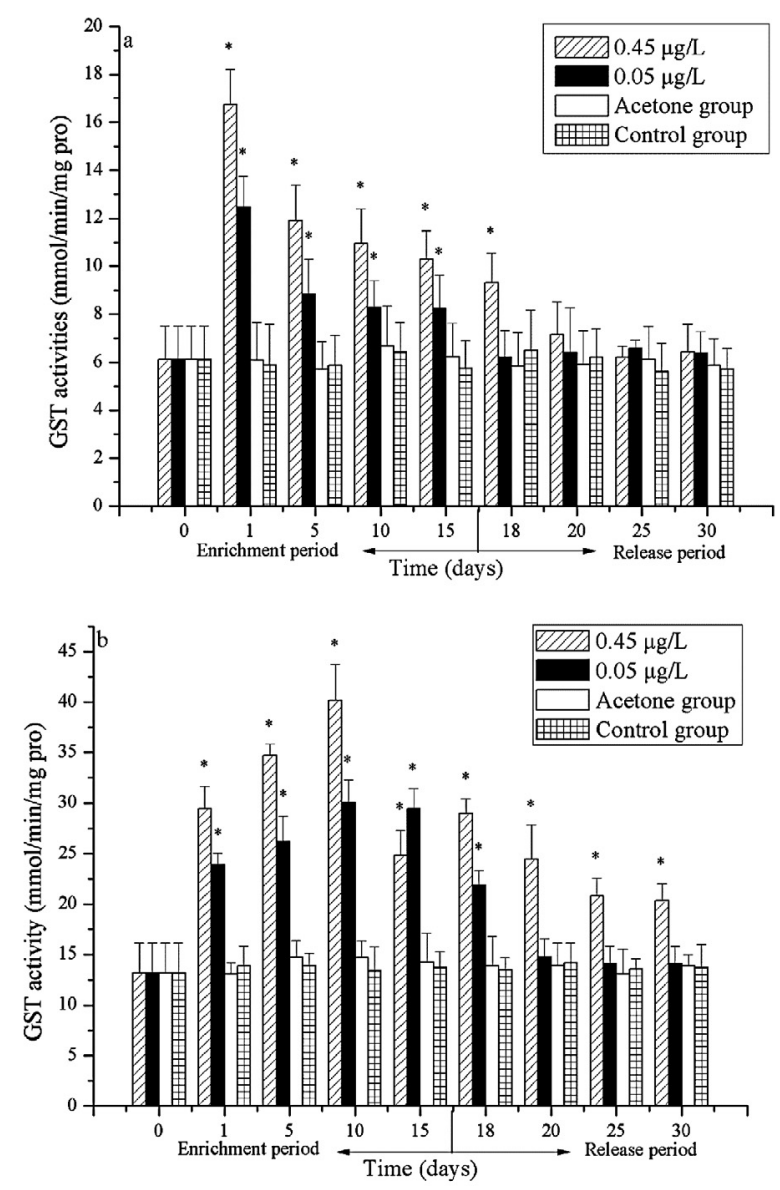

Fig. 2. Effect of BaP on GST activity of gill (a) and liver (b). Note: Single asterisk $(*)$ indicates significant difference between treatment groups and control group $(P<0.05)$ (Same below).

\subsection{BaP induction of GST activity in P. trituberculatus gill and liver}

During the enrichment period, GST activity in the gill and liver of samples in the $0.45 \mu \mathrm{g} \mathrm{L}^{-1}$ and $0.05 \mu \mathrm{g} \mathrm{L}^{-1}$ test groups was significantly induced at day $1(P<0.05)$. GST activity in the gills of samples in the two test groups reached the peaked at day 1. GST activity at day 1 was 2.74 and 2.04 times higher than the activity at day 0. Subsequently, GST activity in the gill continuously declined. GST activity in the gill of the $0.45 \mu \mathrm{g} \mathrm{L}^{-1}$ test group was still significantly higher than in the control group at day $15(P<0.05)$. However, no significant difference was obtained at day $10(P>0.05)$. Gill GST activity of the $0.05 \mu \mathrm{g} \mathrm{L}^{-1}$ test group was stabilized at day 5 $(P<0.05)$. Liver GST activity of the two test groups continuously increased after day 1 , peaking at day 10 . The activity at day 10 was 3.05 and 2.28 times higher than that at day 0 . Then, liver GST activity of the $0.45 \mu \mathrm{g} \mathrm{L}^{-1}$ test group decreased. Even if GST activity in the liver GST activity in the liver of the $0.45 \mu \mathrm{g} \mathrm{L}^{-1}$ test group decreased, the level was still significantly higher than in the control group at day $15(P<0.05)$ and was lower than in the $0.05 \mu \mathrm{g} \mathrm{L}^{-1}$ test group. GST activity in the liver of the $0.05 \mu \mathrm{g} \mathrm{L}^{-1}$ test group was stabilized at day $10(P<0.05)$. During the entire enrichment period,
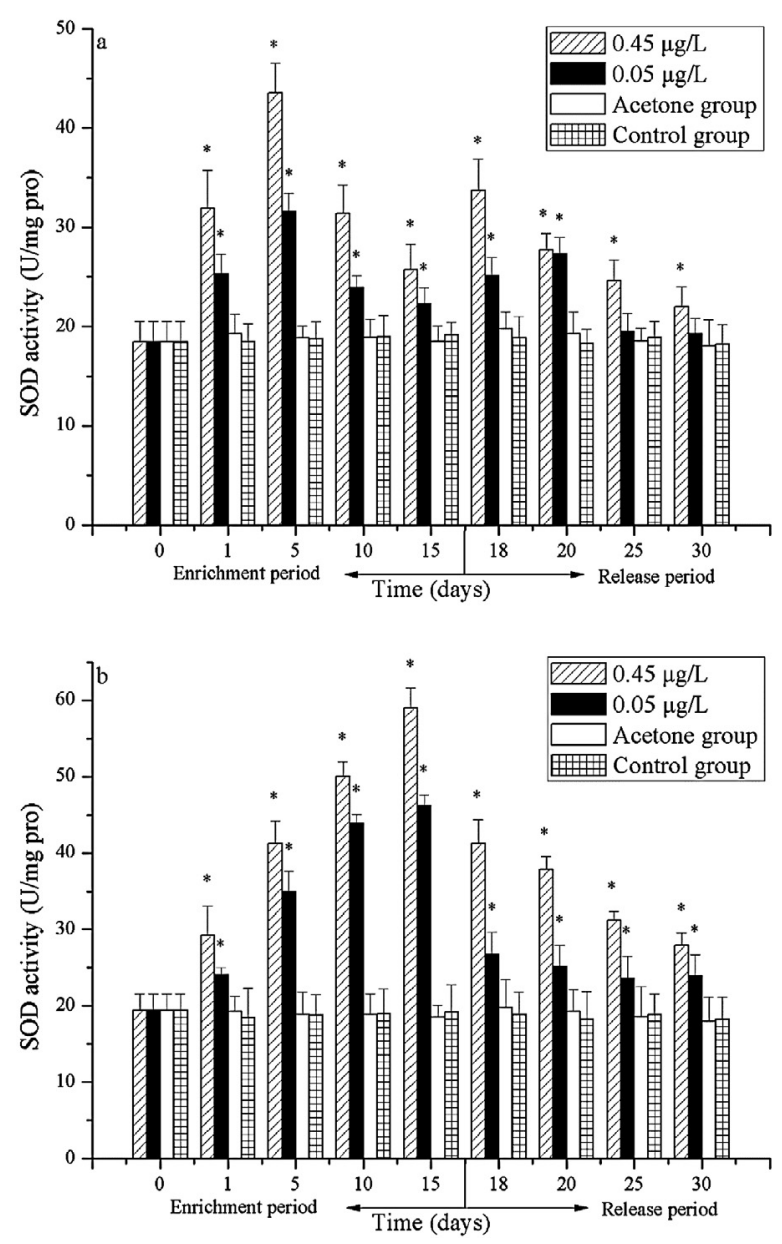

Fig. 3. Effect of BaP on SOD activity of gill (a) and liver (b). Note: Single asterisk $(*)$ indicates significant difference between treatment groups and control group $(P<0.05)$ (same below).

the activity of GST activity in the $0.05 \mu \mathrm{g} \mathrm{L}^{-1}$ test group was less induced than in the $0.45 \mu \mathrm{g} \mathrm{L}^{-1}$ test group. During the release period, the GST activity in the gill and liver of the 0.45 and $0.05 \mu \mathrm{g} \mathrm{L}^{-1}$ test groups continuously decreased. Gill GST activity of the $0.45 \mu \mathrm{g} \mathrm{L}^{-1}$ test group recovered to the level of the control group at day $25(P>0.05)$. By contrast, the GST activity level in the $0.05 \mu \mathrm{g} \mathrm{L}^{-1}$ test group recovered at day 18 $(P>0.05)$. Liver GST activity of the 0.45 the $\mu \mathrm{g} \mathrm{L}^{-1}$ test group was still significantly higher than that in the control group at day $30(P<0.05)$. Liver GST activity of the $0.05 \mu \mathrm{g} \mathrm{L}^{-1}$ test group recovered at day $20(P>0.05)$.

\subsection{Induction of BaP on SOD activity of Portunus trituberculatus gill and liver}

During the enrichment period, SOD activity in the gill and liver of the 0.45 and $0.05 \mu \mathrm{g} \mathrm{L}^{-1}$ test groups was significantly induced at day $1(P<0.05)$. SOD activity continued to increase and peaked at day 5. At day 5, SOD activity was 2.36 and 1.71 times higher than at day 0. Subsequently, SOD activity continuously decreased However, SOD activity in the gill of the two test groups at day 15 was still higher than 

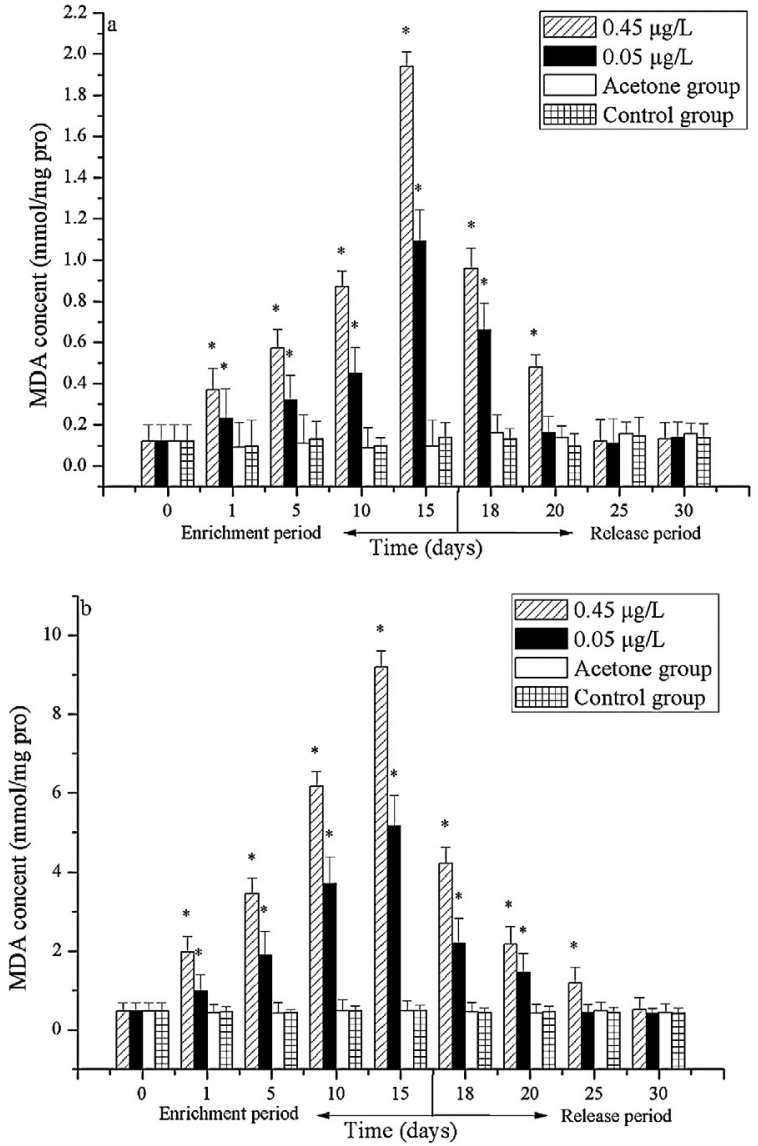

Fig. 4. Effect of BaP on MDA content of gill (a) and liver (b). Note: Single asterisk $(*)$ indicates significant difference between treatment groups and control group $(P<0.05)$ (same below).

that in the control group $(P<0.05)$. Liver SOD activity in both test groups continued to increase after day 1 peaked at day 15 . Liver SOD activity at day 15 was 3.04 and 2.38 times higher than at day 0 and was significantly higher than that of the control group $(P<0.05)$. During the entire enrichment period, the SOD activity in the $0.05 \mu \mathrm{g} \mathrm{L}^{-1}$ test group was less induced than in the $0.45 \mu \mathrm{g} \mathrm{L}^{-1}$ test group. During the release period, SOD activity in the gill of the two test groups showed an inverted V-shaped variation. The $0.45 \mu \mathrm{g} \mathrm{L}^{-1}$ test group showed significantly higher gill SOD activity than the control group $(P<0.05)$, and the $0.05 \mu \mathrm{g} \mathrm{L}^{-1}$ test group could recover to the level of the control group at day 25. SOD activity in the liver of the two test groups continued to decline. However, activity was still significantly higher than in the control group at day 30 $(P<0.05)$.

\subsection{BaP effect on MDA content of $P$. trituberculatus gill and liver}

During the enrichment period, MDA content in the gill and liver of 0.45 and $0.05 \mu \mathrm{g} \mathrm{L}^{-1}$ test groups at day 1 significantly and continuously increased $(P<0.05)$. Content was highest at day 15 Content was $16.18,9.10,19.39$, and 10.90 times higher at day 15 than at day 0. During the entire enrichment period,
MDA content in the gill and liver of the $0.05 \mu \mathrm{g} \mathrm{L^{-1 }}$ group was lower than that of the $0.45 \mu \mathrm{g} \mathrm{L}^{-1}$ test group. During the release period, gill MDA contents of the two test groups continuously decreased. The gill MDA content in the $0.45 \mu \mathrm{g} \mathrm{L}^{-1}$ test group recovered to the level of the control group at day 25 $(P>0.05)$, and that in the $0.05 \mu \mathrm{g} \mathrm{L}^{-1}$ test group recovered at day $20(P>0.05)$. Liver MDA content in the $0.45 \mu \mathrm{g} \mathrm{L}^{-1}$ test group recovered to the level of the control group at day 30 $(P>0.05)$ By contrast, liver MDA content in the $0.05 \mu \mathrm{g} \mathrm{L}^{-1}$ test group recovered at day $25(P>0.05)$.

\section{Discussion}

$\mathrm{BaP}$ can highly induce cytochrome P4501A: thus, BaP could induce its own metabolism (Eberhart et al. 1992). EROD is a typical phase I metabolic enzyme of mixed function oxygenases (MFO) that cytochrome P450 depends on. EROD can induce be induced by xenobiotic pollutants, such as BaP, PAHs, and polychlorinated biphenyls. EROD can catalyze degradation of endogenous and exogenous liposoluble substrates in organisms. EROD is a sensitive enzyme index for evaluating biotoxicity of organic pollution and is a real response parameter of living organisms exposed to polluted environments (Gravato et al. 2002; Gagnon et al. 2000). In the subsequent phase II reaction, endogenous water soluble molecules such as glutathione (GSH) combine with phase I metabolites under GST's catalytic effect. Thus, liposoluble substances are converted to water soluble ones These substances are then discharged from living bodies. This is the GST's detoxification mechanism. GST expression level is vital to a cell's sensitivity to chemical substances (Fitzpatrick et al. 1995; Gadagbui et al. 2000). In the present study, gill and liver of the $0.45 \mu \mathrm{g} \mathrm{L}^{-1}$ test group showed stronger EROD and GST induction than the $0.05 \mu \mathrm{g} \mathrm{L}^{-1}$ test group during the enrichment period. Thus, a dosage-effect relationship was shown. The positive correlation of EROD and GST activities with organic pollution concentration has been confirmed by studies on fish (OrtizDelgadoa et al. 2008) and shellfish (Ren et al. 2015). EROD and GST activities in the gill and liver of the two test groups showed certain synchronous variation trends, which were both in bell-shaped curves, during the experiment. Both test groups achieved the highest EROD and GST induction levels simultaneously. However, the highest EROD and GST induction levels were achieve faster in the gill than in the liver. Thus, the gill showed higher sensitivity to $\mathrm{BaP}$ than the liver. Meanwhile, the highest EROD and GST activities in the gill were lower than those in the liver. The gill is in direct contact with pollutants and is an important intra-site for pollutant absorption (Jonsson et al. 2006). However, the liver, which participates in immunoreactions and where metabolism and detoxification of many endogenous and exogenous compounds occur, is more active in metabolic transformation (Chen et al. 2008). A study by Santos et al. (2004) also confirmed that compared with Anguilla anguilla gill and kidney, the liver has stronger detoxification and higher metabolism level. EROD and GST activities in the gill and liver of the two test groups decreased after reaching the peak levels. However, even at decreased levels, the activities of these enzymes were still much higher than those in the control groups $(P<0.05)$. In $\mathrm{BaP}$ accumulation, 
a decrease in enzyme activity signified that the intermediate metabolite generated by $\mathrm{BaP}$ exceeded the detoxification capability of EROD and GST, thus, the configuration of related expressed genes changed (Sol et al. 2001). Finally, EROD and GST activities were inhibited. Such reaction is universal among mammals, birds, and fishes (Munkittrick et al. 1995). At the end of the release period, EROD and GST activities in the gill and liver of both test groups, except for the liver GST activity of the $0.45 \mu \mathrm{g} \mathrm{L}^{-1}$ test group, could recover to the level of the control group and remain stable $(P>0.05)$. This finding implies that even if EROD and GST activities are inhibited starting from late enrichment period, no irreversible damage exists. Moreover, the activities of both enzymes could achieve normal levels through the repair capability of $P$. trituberculatus. The $0.45 \mu \mathrm{g} \mathrm{L}^{-1}$ test group had significantly higher liver GST activity than the control group $(P<0.05)$. Thus, the liver still had a certain amount of $\mathrm{BaP}$ after release for day 15 . This finding further confirmed that living organisms cannot easily metabolize $\mathrm{BaP}$ completely. This finding agreed with the experimental results of $\mathrm{BaP}$ enrichment and release in marine shellfish (Wang et al. 2011).

Pollutants can generate reactive oxygen species (ROS) and $\mathrm{H}_{2} \mathrm{O}_{2}$ during phase I and phase II conversions. Delayed elimination of ROS and $\mathrm{H}_{2} \mathrm{O}_{2}$ can therefore oxidative damages to a living body. SOD plays an important role in preventing oxidative damages converts $\mathrm{O}_{2-}$ into $\mathrm{H}_{2} \mathrm{O}_{2}$ and is the best marker of induced oxidative stress response to pollutants (Thomas et al. 1990). SOD exists in all aerobic tissues the strongest SOD activity in the liver and kidney tissues (Rey-Salgueiro et al. 2011). In this present study, SOD activities in the gill of two test groups varied in bell-shaped curves during the enrichment period SOD activities in the liver continuously increased and presented a certain dosage-effect relationship. This result for SOD was the same as the results for EROD and GST activities. Similarly, the highest SOD activity was obtained quicker in the gill than in the liver, and the gill had lower maximum SOD activity than the liver. This finding confirmed that the gill is more sensitive to $\mathrm{BaP}$ than the liver. Enzyme activity inhibition is easier in the gill than in the liver. In both test groups, SOD activity in the gill declined after reaching the peak level. Although the decreased SOD activity was still higher than in the control group at day $15(P<0.05)$, abundant ROS was present. SOD activity showed an imbalance with ROS elimination and production. Consequently, SOD activity is inhibited. During the release period, gill SOD activity initially increased and then gradually decreased. The phenomenon may be due to the high sensitivity of SOD activity. Living bodies could respond to "excessive stress" within a certain range after pollutant exposure. SOD activity in the gill of the $0.05 \mu \mathrm{g} \mathrm{L} \mathrm{L}^{-1}$ test group could recover to the level of the control group $(P>0.05)$. By contrast, gill SOD activity of the $0.45 \mu \mathrm{g} \mathrm{L}^{-1}$ test group could not recover. The two test groups had significantly higher SOD activity in the liver than the control group $(P<0.05)$. Thus, a considerable amount of $\mathrm{BaP}$ remained in the gill and liver after being released for day 15 .

The LPO effect is due to serious pollution, which exceeds and even inhibits the oxidation resistance of an enzyme system. Thus, biological membrane damage, DNA damage, and enzyme inactivation occur. LPO effect is closely related to antioxidase. LPO level can be expressed by MDA content, which is an index of cell membrane oxidative damage (Thomas et al. 1990). During the enrichment period, MDA contents in both test groups increased dramatically $(P<0.05)$ at day 1 and continued to increase, thereby implying that LPO effect was generated and became increasingly seriously. Serious LPO effect occurs in the liver, which is the center of detoxification and metabolism. Subsequently, LPO level continued to increase with increasing ROS. At the end of the release period, MDA content in both test groups recovered to the level of the control group $(P>0.05)$. During the release period, $\mathrm{BaP}$ was charged continuously and ROS production decreased accordingly. Thus, the stress on the antioxidant system is alleviated. The recovery of antioxidant enzyme (e.g., SOD) activity is enabled. Compared with the gill, the liver takes longer to recover and reach the MDA content of the control group. Liver, which is the main organ of detoxification and metabolism, has higher LPO level than the gill. Additionally, oxidative damages caused by a certain range of $\mathrm{BaP}$ stress concentration at a certain time range are reversible.

\section{Conclusion}

During BaP enrichment, the toxicological indices of gill and liver of the two test groups were significantly induced at day $1(P<0.05)$. The degree of induction is positively proportional to exposure concentration. The EROD and GST activities in the gill and liver increased initially and subsequently decreased. Gill SOD activity also increased initially and subsequently decreased. By contrast, liver SOD activity continuously increased. The MDA content in both gill and liver also continuously increased. At release, gill SOD activity of the $0.45 \mu \mathrm{g} \mathrm{L}^{-1}$ test group and liver SOD activity in both test groups were still significantly higher than those in the control group $(P<0.05)$. Gill and liver could recover to normal levels of the toxicological indices $(P>0.05)$. Gill has lower maximum EROD, GST, and SOD activities and MDA content than the liver.

Acknowledgements. This work was supported by the Special Scientific Research Funds for Central Non-profit Institutes, Chinese Academy of Fishery Sciences (No. 2014T06), the Special Scientific Research Funds for Central Non-profit Institutes, Chinese Academy of Fishery Sciences (No. 2014A02XK01), professional project on special key technology for oil spill for Ministry of agriculture (No. 2012-NZ-5739), and National modern agricultural industry technology system construction project (No.CARS-48).

\section{References}

Akcha F., Izuel C., Venier P., et al. 2000, Enzymatic biomarker measurement and study of DNA adduct formation in benzo. Aquat. Toxicol. 49, 269-287.

Beyer J., Sandvik M., Hylland K., et al. 1996, Contaminant accumulation and biomarker responses in flounder (Platichthys flesus L.) and Atlantic cod (Gadus morhua L.) exposed by caging to polluted sediments in Sørfjorden, Norway. Aquat. Toxicol. 36, 75-98. 
Bo J., Gopalakrishnan S., Fan, D.Q., et al. 2012, Benzo[a]pyrene modulation of acute immunologic responses in red Sea bream pretreated with lipopolysaccharide. Environ. Toxicol. 29, 517525.

Carlson E.A., Li Y., Zelikoff J.T. 2002, Exposure of Japanese medaka (Oryzias latipes) to benzo[a]pyrene suppresses immune function and host resistance against bacterial challenge. Aquat. Toxicol. 56, 289-301.

Chen M.L., Qu J.Y., Liu Q.B., et al. 2008, Effects of tetrabromobisphenol A and pentabromophenol on the liver histological and ultra microstructure of Carassius auratus. J. Safety Environ. 8, $8-11$.

Eberhart J., Coffing S.L., Anderson J.N., et al. 1992, The timedependent increase in the binding of benzo[a]pyrene to DNA through (+)-anti-benzo[a]pyrene-7,8-diol-9,10-epoxide in primary rat hepatocyte cultures results from induction of cytochrome P450IA1 by benzo[a]pyrene treatment. Carcinogenesis 13, 297-301.

Ferreira A.M., Vale C. 1998, PCB accumulation and alterations of lipids in two length classes of the oyster Crassostrea angulata and of the clam Ruditapes decussatus. Marine Environ. Res. 45, 259-268.

Fitzpatrick P.J., Sheehan D., Livingstone D.R. 1995, Studies on isoenzymes of glutathione S-transferase in the digestive gland of Mytilus galloprovincialis with exposure to pollution. Marine Environ. Res. 39, 241-244.

Gadagbui B.K., James M.O. 2000, Activities of affinity-isolated glutathione S-transferase (GST) from channel catfish whole intestine. Aquat. Toxicol. 49, 27-37.

Gagnon M.M., Holdway D.A. 2000, EROD induction and biliary metabolite excretion following exposure to the water accommodated fraction of crude oil and to chemically dispersed crude oil. Archives Environ. Contamin. Toxicol. 38, 70-77.

Gopalakrishnan S., Thilagam H., Huang W.B., et al. 2009, Immunomodulation in the marine gastropod Haliotis diversicolor exposed to benzo(a)pyrene. Chemosphere 75, 389-397.

Gravato C., Santos M.A. 2002, Juvenile sea bass liver P450, EROD induction, and erythrocytic genotoxic responses to PAH and PAH-like compounds. Ecotoxicol. Environ. Safety 51, 115-127.

Habig W.H., Pabst M.J., Jakoby W.B. 1974, Glutathione Stransferases the first enzymatic step in mercapturic acid formation. J. Biol. Chem. 249, 7130-7139.

Huang, W., Wang, Z., Yan, W., 2012, Distribution and sources of polycyclic aromatic hydrocarbons (PAHs) in sediments from Zhanjiang Bay and Leizhou Bay, South China. Marine Pollution Bulletin 64, 1962-1969.

Jonsson E.M., Abrahamson A., Brunstrom B., et al. 2006, Cytochrome P4501A induction in rainbow trout gills and liver following exposure to waterborne indigo, benzo[a]pyrene and 3 , 3', 4, 4', 5-pentachlorobiphenyl. Aquat. Toxicol. 79, 226-232.

Kidd K.A., Hesslein R.H., Ross B.J., et al. 1998, Bioaccumulation of organochlorines through a remote freshwater food web in the Canadian Arctic. Environ. Pollution 102, 91-103.

Lemaire P., Förlin L., Livingstone D.R. 1996, Responses of hepatic biotransformation and antioxidant enzymes to CYP1Ainducers (3-methylcholanthrene, $\beta$-naphthoflavone) in sea bass (Dicentrarchus labrax), dab (Limanda limanda) and rainbow trout (Oncorhynchus mykiss). Aquat. Toxicol. 36, 141-160.

Lisa L., Valerio M., Maria G.M. 2009, Biomarker responses in the crab Carcinus aestuarii to assess environmental pollution in the Lagoon of Venice (Italy). Ecotoxicology 18, 869-877.
Munkittrick K.K., Blunt B.R., Leggett M., et al. 1995, Development of a sediment bioassay to determine bioavailability of PAHs to fish. J. Aquat. Ecosyst. Health 4, 169-181.

Orbea A., Ortiz-Zarragoitia M., Solé M., et al. 2002, Antioxidant enzymes and peroxisome proliferation in relation to contaminant body burdens of PAHs and PCBs in bivalve molluscs, crabs and fish from the Urdaibai and Plentzia estuaries (Bay of Biscay). Aquat. Toxicol. 58, 75-98.

Ortiz-Delgadoa J.B., Behrensb A., Segner H., et al. 2008, Tissuespecific induction of EROD activity and CYP1A protein in Sparus aurata exposed to B(a)P and TCDD. Ecotoxicol. Environ. Safety 69, 80-88.

Pereira T.C., Ferreira R.A., Nogueira L., et al. 2010, Biochemical biomarkers in Oreochromis niloticus exposed to mixtures of benzo [a] pyrene and diazinon. Ecotoxicol. Environ. Safety 73, 858-863.

Pohl R.J., Fouts J.R. 1980, A rapid method for assaying the metabolism of 7-ethoxyresorufin by microsomal subcellular fractions. Anal. Biochem. 107, 150-155.

Ren Xianyun, Pan Luqing, Wang Lin, 2015. Toxic effects upon exposure to benzo[a]pyrene in juvenile white shrimp Litopenaeus vannamei. Environ. Toxicol. Pharmacol. 39, 194-207.

Rey-Salgueiro, L., Costa, J., Ferreira, M., et al. 2011, Evaluation of 3-hydroxy-benzo(a)pyrene levels in Nile Tilapia (Oreochromis niloticus) after waterborne exposure to $\operatorname{Benzo}(a)$ pyrene. Toxicol. Environ. Chem. 10, 2040-2054.

Reynaud S., Deschaux P. 2006. The effects of polycyclic aromatic hydrocarbons on the immune system of fish: a review. Aquat. Toxicol. 77, 229-238.

Santos M.A., Pacheco M., Ahmad I. 2004, Anguilla anguilla L. antioxidants responses to in situ bleached kraft pulp mill effluent outlet exposure. Environ. Int. 30, 301-308.

Silva C., Oliveira C., Gravato C., et al. 2013, Behaviour and biomarkers as tools to assess the acute toxicity of benzo (a) pyrene in the common prawn Palaemon serratus. Marine Environ. Res. 90, 39-46.

Sol E.M., Porte C., Albaig E.S.J. 2001, Hydrocarbons, PCBs and DDT in the NW Mediterranean deep-sea fish Mora moro. Deep Sea Research Part I: Oceanographic Research Papers 48, 495513.

Thomas J.P., Maiorino M., Ursini F., et al. 1990, Protective action of phospholipid hydroperoxide glutathione peroxidase against membrane-damaging lipid peroxidation. In situ reduction of phospholipid and cholesterol hydroperoxides. J. Biol. Chem. 265, 454-461.

van Oosterom J., Codi K.S., Negri A., et al. 2010, Investigation of the mud crab (Scylla serrata) as a potential bio-monitoring species for tropical coastal marine environments of Australia. Marine Pollution Bulletin 60, 283-290.

Wang L., Pan L.Q., Liu N., et al. 2011, Biomarkers and bioaccumulation of clam Ruditapes philippinarum in response to combined cadmium and benzo[ $[a]$ pyrene exposure. Food Chem. Toxicol. 49, 3407-3417.

Walker C.H. 1998, The use of biomarkers to measure the interactive effects of chemicals. Ecotoxicol. Environ. Safety 40, 65-70.

Xu Q.H., Liu Y. 2011, Gene expression profiles of the swimming crab Portunus trituberculatus exposed to salinity stress. Marine Biol. 158, 2161-2172. 